\title{
Innovative technological and technical support of grain production for the forest-steppe zone of Siberia
}

\author{
Boris Dokin ${ }^{1}$, Oleg Elkin ${ }^{1}$, Anna Aletdinova ${ }^{2, *}$ and Argen Mozonov ${ }^{3}$ \\ ${ }^{1}$ Siberian Federal Research Center for Agrobiotechnologies of the Russian Academy of Sciences, \\ Novosibirsk region, 630501, Krasnoobsk, Russia \\ ${ }^{2}$ Novosibirsk State Technical University, 20, Karl Marx Avenue, 630073, Novosibirsk, Russia \\ ${ }^{3}$ Novosibirsk State Agrarian University, 160, Dobrolyubova str., 630039, Novosibirsk, Russia
}

\begin{abstract}
The purchase of agricultural machinery should be determined by technological and technical policies. The purpose of the study is to increase the efficiency of grain production through the use of innovative resource-saving technologies and equipment. The solution of this problem includes the definition of model farms that characterize the soil and production conditions of the forest-steppe zone of Siberia, the development of mathematical tools, the calculation of promising compositions of the machine and tractor fleet and alternative options for grain production technologies, depending on the availability of agricultural producers with resources. It allowed us to establish that if a commodity producer can spend 10-12 thousand rubles per 1 ha of grain crops on chemization and has 4 machine operators per 1000 ha of grain crops, then it can work on the classical intensive technology based on dump plowing and or deep loosening; if at the same level of chemization per 1 ha of grain crops and has 3 machine operators per 1000 ha of grain crops,then it must switch to intensive resource-saving technology at minimum or zero tillage. Switching to more energy-intensive tractors and resource-saving technologies allows you to save fuel by $30-35 \%$, personnel by $1.5-2.5$ times, and operating costs by $10-15 \%$.
\end{abstract}

\section{Introduction}

Over the past decades, Russia has changed its social system and farming system, new resource-saving technologies based on minimum and zero tillage have appeared, and the number of energy-saturated tractors, forage and grain harvesters, and wide-range sowing complexes has increased. This required new methodological approaches to choosing alternative technologies and machine complexes depending on the resource availability of the producers themselves.

Scientific works on their development, improvement and application can be divided into three groups of articles:

- dedicated to the mathematical formulation of the optimization problem [1-5];

\footnotetext{
*Corresponding author:aletdinova@corp.nstu.ru
} 
- on the development of information systems for management decision-making [6-10];

- to set out practical recommendations [11-13].

According to Belarusian scientists, it is necessary to improve the efficiency of agricultural production on the basis of strategic planning in the field of technical equipment of enterprises [14]. We support this statement, but we emphasize the need for a systematic approach. Agricultural producers need practical recommendations, and it is important for scientists to understand how changing decision criteria changes the structure and composition of the machine and tractor fleet.

This article was a continuation of our article "Prediction method of the variations of annual field work complexes and its implementation", which revealed the method we use for end-to-end views of the variants of field work complexes [15]. We focus on the obtained simulation results.

\section{Materials and methods}

In Russia, scientific and technical programs for the development of agriculture have been developed and implemented at the state and regional levels. In particular, in the Novosibirsk region, scientists and agricultural producers are creating "Program of machinetechnological modernization of the agro-industrial complex of the Novosibirsk region until 2025". Its goal is to increase the efficiency of grain production in the forest-steppe zone of Siberia through the use of resource-saving technologies and innovative types of equipment.

\subsection{Characteristics of a model farm for grain production}

Regions of Russia are characterized by natural and economic diversity; they have their own original features, internal specialization, climatic and geographical features. There are eight soil and climate zones on the territory of Siberia, which determines various agricultural technologies. The forest-steppe soil-climatic zone is the most common in the regions of Siberia. For example, in the Novosibirsk region there are forest-steppe, steppe and deciduous forest zones. In our study, the model farm is characterized by typical soil and climate conditions of the Novosibirsk region, specialization and structure of sown areas. Therefore, the soil-production conditions of the forest-steppe zone subzone are characterized by three model farms with their sown area structures.

The distribution of agricultural organizations in the Novosibirsk region by arable land area is shown in figure 1. For example, in the Novosibirsk region, medium-sized agricultural organizations dominate in terms of land use (they make up about $53.9 \%$ ), which have an area of arable land from 3000-7000 ha (figure 1). Such farms contain from 500 to 1000 conventional heads of livestock, to perform all mechanized work in agrotechnical terms and care for animals, the fleet of self-propelled vehicles must be within the range of 43 to 100 physical units. 


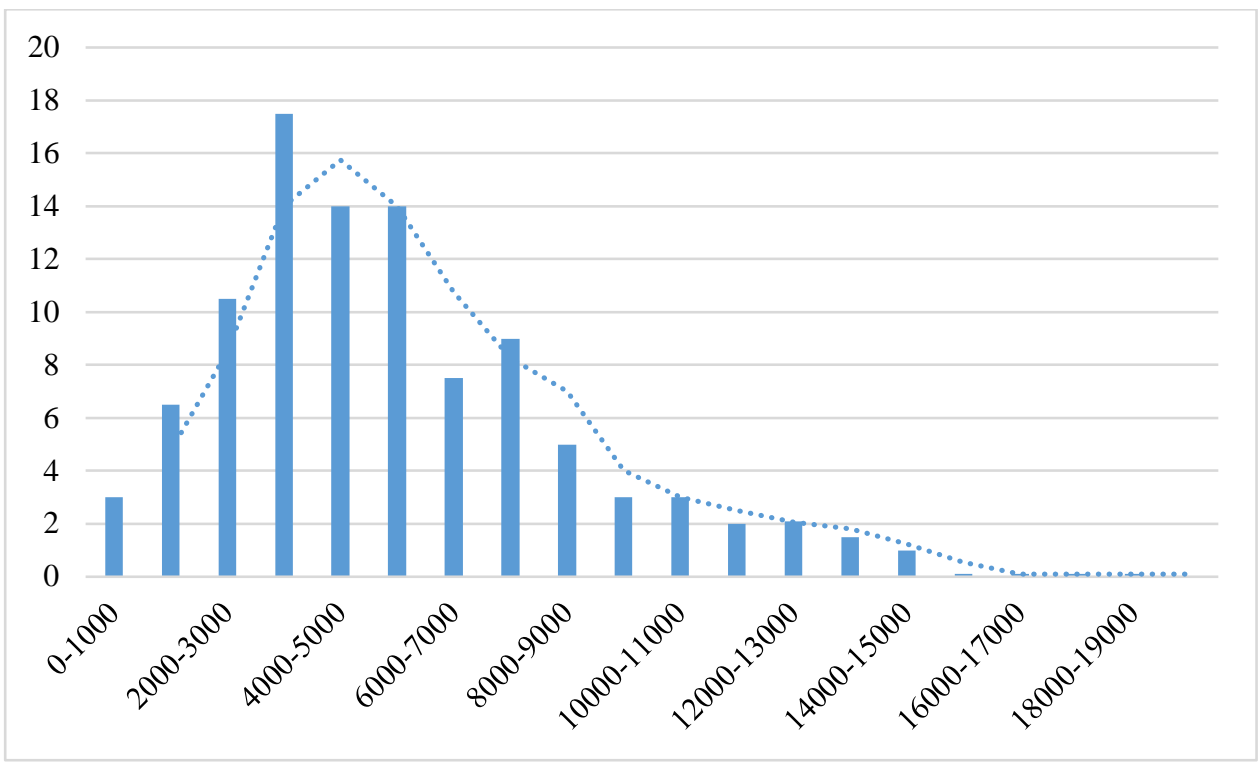

Fig. 1. Distribution of agricultural organizations in the Novosibirsk region by arable land area, $\%$.

The number of agricultural organizations of grain and cattle breeding with arable land sizes from 1000-3000 hectares and a self-propelled vehicles fleet from 15 to 42 physical units, and less than 500 conventional heads of cattle in the Novosibirsk region is $17.6 \%$. Medium-sized and large agricultural organizations with 7000-11000 hectares of arable land (about $19.4 \%$ of such farms in the region), a fleet of self-propelled vehicles with more than 40-80 physical units and from 1000-1500 conventional heads of livestock.

Large agricultural organizations with an area of arable land from 11000 to 15000 hectares of arable land that have more than 1,500 conventional heads of livestock (their share in the total composition is small - about 4.5\%), they need $80-120$ pieces of selfpropelled vehicles.

Based on the results obtained and existing developments, the justification and selection of the size of the model farm for the production of grain was carried out.

In particular, in the Northern forest-steppe zone of the Novosibirsk region, about $50 \%$ of agricultural organizations have an area of arable land in the range from 3000 to 6000 hectares (in the region of such organizations, about $43.0 \%$ ). Based on the available information, as well as existing developments, the average size of land use can be taken as a model farm with a total area of 10000 hectares of agricultural land for grain and cattle breeding. The area of arable land under consideration is 6000 hectares, the number of cattle is within 2500 heads (including a herd of dairy cows is about 1000 heads). At the same time, the area occupied under crops is approximately $78 \%$ of the total area of arable land (4700 ha). Of these, there are 3,200 hectares for grain crops, about 1,500 hectares for forage crops, including 250 hectares for silage crops, 600 hectares for perennial grasses, 450 hectares for annual grasses, and 200 hectares for industrial crops.

\subsection{Method for substantiating promising compositions of a machine and tractor fleet (MTF) for model farms}

The prediction method of the variations of annual field work complexes is the basis of the method for substantiating the perspective compositions of the machine and tractor fleet of model farms. 
The principle of forming annual field work complexes is as follows [15]. A basic plan for performing field work during the year with General-purpose tractors is drawn up. Let's assume that a tractor of class 3 , for example, begins to perform this volume. From the total amount of field work, the first tractor will take a volume equal to the productivity of the machine-tractor aggregate (MTA) with this tractor in this agricultural operation for each technological operation. Thus, the first annual set of field works was obtained. According to the same principle, the second tractor will get a second annual set of field work. The last annual set of field work will correspond to the full implementation of the entire volume of field work. Tractors of class 5 and 8 will collect their annual field work complexes in accordance with the performance of the machine and tractor aggregate on the same agricultural operations.

Economic indicators are determined for each technology and composition of the machine and tractor fleet. For tilled tractors, the diagram shows your basic plan for performing field work during the year. According to the same principle, the formation of annual field work complexes is done (Fig. 2).

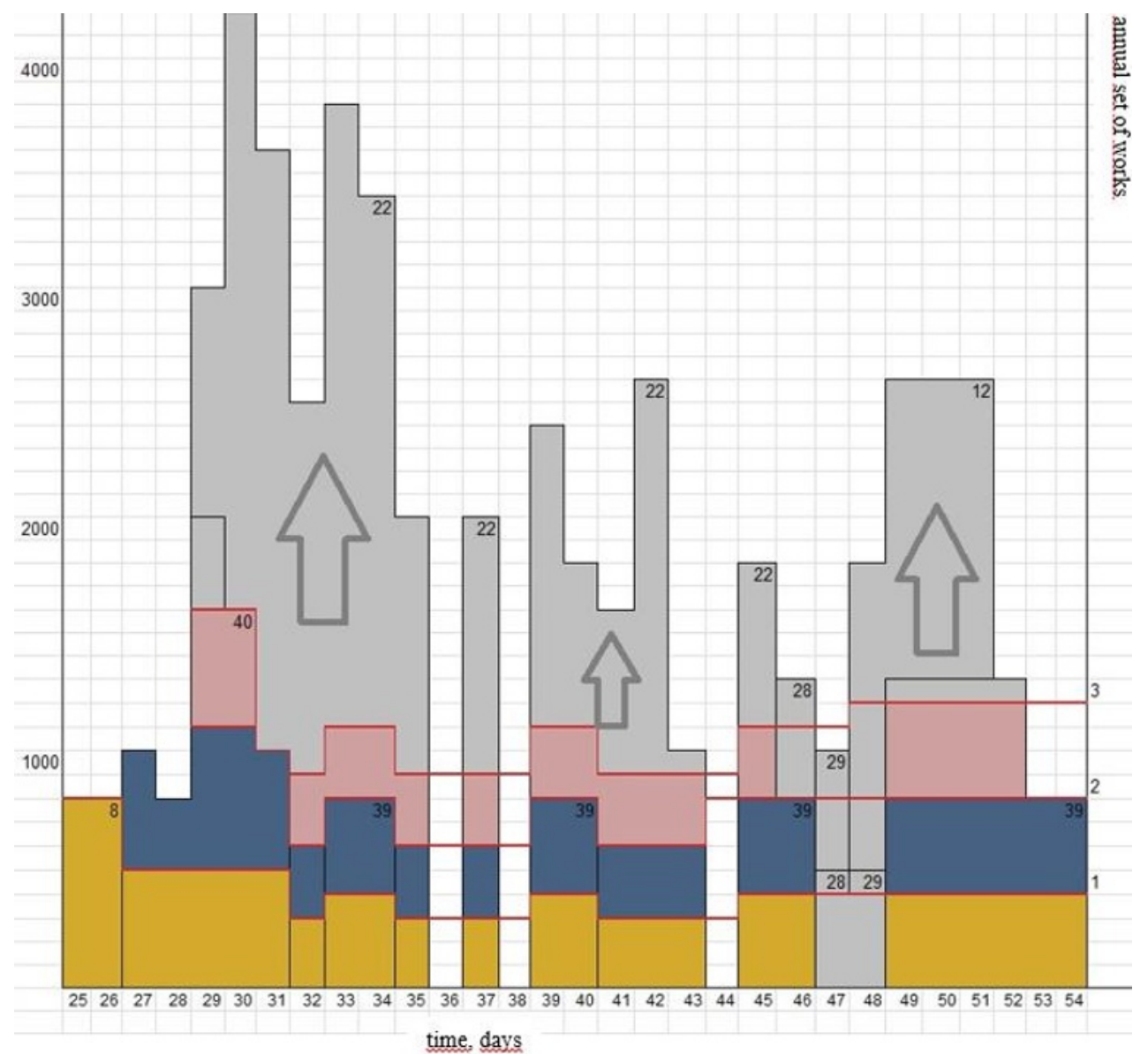

Fig. 2. Loading tractors for intensive technology (based on minimal tillage). Operation numbers: 8Early spring harrowing; 39-Minimum tillage of 10-12 cm; 28-Mowing into rolls; 29-Threshing of rolls with straw piling; 12-Direct combine with straw spreading harrowing; 40-Combined pre-sowing tillage and sowing; 22-Spraying.

Machine-tractor aggregate with a class 5 tractor can sow 50 ha in a ten-hour shift, and 
MTA units with a class 8 tractor can sow 200-250 ha in 24 hours. At the same time, they work using GLONASS / GPS navigation systems [16]. The principle of parallel driving allows you to avoid replanting and save seeds, herbicides and pesticides.

\section{Results}

You can work with the simplest technologies, having an inexpensive machine and tractor fleet and low cost of grain, but this will require more machine operators, since there will be the lowest level of labor productivity. Energy-intensive equipment will require large investments, but will increase productivity by two or three times. Each agricultural producer chooses a variant of technologies and technical means for the production of grain, depending on the resource supply and the availability of machine operators. The authors show the results of comparison of technologies for cultivation of grain crops on the example of a model economy of the southern forest-steppe in table 1 ( $1 \mathrm{USD} \approx 63 \mathrm{Rub}$ ).

Table 1. Comparative analysis of grain production technologies.

\begin{tabular}{|c|c|c|c|c|}
\hline \multirow{2}{*}{ Indicators } & \multirow{2}{*}{ Unit } & \multicolumn{3}{|c|}{ Technology } \\
\hline & & Classical & Mini-till & No-till \\
\hline Yield & t/ha & 5.5 & 5.5 & 3.5 \\
\hline $\begin{array}{l}\text { Number of } \\
\text { machine } \\
\text { operators }\end{array}$ & people & 4 & 3 & 2 \\
\hline $\begin{array}{l}\text { Operating costs } \\
\text { per } 1 \text { ha }\end{array}$ & $\begin{array}{l}\text { thousand } \\
\text { rubles/ ha }\end{array}$ & 18.8 & 17.02 & 15.842 \\
\hline Production cost & $\begin{array}{l}\text { thousand } \\
\text { rubles/ } \\
\text { ton }\end{array}$ & 3.418 & 3.094 & 4.526 \\
\hline Labor costs & peoplelha & 1438.6 & 1046.1 & 912 \\
\hline Labor costs & peoplelton & 0.26 & 0.19 & 0.26 \\
\hline $\begin{array}{l}\text { The cost of fuel } \\
\text { and lubricants }\end{array}$ & $\mathrm{kg} / \mathrm{ha}$ & 48.2 & 38.4 & 30.1 \\
\hline
\end{tabular}

The minimum cost of the technology is based on minimum tillage, but the agricultural producer will choose the "No-Till" technology if he has only 2 machine operators per 1000 hectares of grain crops.

The number of machine operators in agricultural production in the Novosibirsk region has decreased by more than 5 times over the past 20 years. Therefore, we see the following solutions to reduce the need for human resources for machine operators.

The first solution is to switch to more energy-intensive tractors (from class 3 to class 5 ... 8). This is well illustrated by the example calculations in table 2 .

Table 2. The cost of the machine and tractor fleet, operating costs and the need for machine operators for intensive technology based on dump plowing.

\begin{tabular}{|c|c|c|c|}
\hline \multirow{2}{*}{ Indicators } & \multicolumn{3}{|c|}{ Make of tractor } \\
\cline { 2 - 4 } & K-744P3 & МT3-1822.3 & ДТ-75M \\
\hline $\begin{array}{c}\text { The cost of MTF, million } \\
\text { rubles }\end{array}$ & 102.36 & 72.85 & 67.98 \\
\hline $\begin{array}{c}\text { Operating cost, million } \\
\text { rubles }\end{array}$ & 33.88 & 25.17 & 21.85 \\
\hline
\end{tabular}




\begin{tabular}{|c|c|c|c|}
\hline $\begin{array}{c}\text { The need for tractor } \\
\text { operators, people }\end{array}$ & 14 & 17 & 26 \\
\hline
\end{tabular}

The model economy of the forest-steppe zone has the following structure of sown areas: arable land-11600 ha, grain - 5906, annual grasses-1751, perennial grasses-2268, pairs 1735 ha. The authors justified the composition of the machine and tractor fleet for the classical intensive technology based on dump plowing.

The second solution is to switch to resource-saving technologies based on minimum and zero tillage. According to our calculations, this transition will reduce the need for tractor operators by $1.5 \ldots 2.5$ times (table 3 ).

Table 3. The cost of the machine and tractor fleet, operating costs and the need for machine operators for resource-saving technology based on minimal tillage.

\begin{tabular}{|c|c|c|c|}
\hline \multirow{2}{*}{ Indicators } & \multicolumn{3}{|c|}{ Make of tractor } \\
\cline { 2 - 4 } & K-744P1 & MTZ -1822.3 & John Deere 9430 \\
\hline The cost of MTF, million rubles & 65.73 & 61.84 & 61.26 \\
\hline Operating cost, million rubles & 16.99 & 13.151 & 25.67 \\
\hline The need for tractor operators, people & 6 & 10 & 2 \\
\hline
\end{tabular}

The third solution is to use zero tillage. The development of new technologies creates the fourth solution - performing technological operations using robotics [16].

\section{Discussion}

As a result of the simulation of grain production on model farms for the forest-steppe zone of Siberia, the authors proved that if an agricultural producer can spend 10-12 thousand rubles per 1 ha of grain crops on chemization and has 4 tractor operators per 1000 ha of grain crops, then he can use the classic intensive technology based on dump plowing or deep loosening. If an agricultural producer has the same level of chemicalization, but only 3 tractor operators per 1000 hectares of grain crops, then he must choose an intensive resource-saving technology based on minimal soil treatment. If there are only 2 tractor operators for processing 1000 ha of grain crops, we recommend choosing zero tillage.

As can be seen from tables 2 and 3, if agricultural producers start using more energyintensive tractors using resource-saving technologies, they will reduce fuel consumption by $30-35 \%$, operating costs by $10-15 \%$, and reduce the need for tractor operators by $1.5-2.5$ times.

We see promising areas of research in the combination of soil survey maps for the presence of nutrient components and yield maps of individual areas of the field issued after harvest, in technologies for differentiated application of mineral fertilizers with innovative technical means (this can also be said about differentiated application of herbicides, pesticides and fungicides), the development of agricultural robotics, web management and monitoring of grain production.

\section{Conclusion}

Thus, the method of selecting technologies and complexes of machines for agricultural producers, depending on their resource availability, includes:

- defining the characteristics of a model agricultural economy;

- prediction method of the variations of annual field work complexes;

- making management decisions based on simulation results. 
In Russia, one of the problems remains the shortage of tractor operators. The authors were able to identify four techniques for solving the problem of selecting technologies and technical means for grain production, depending on the resource supply and the availability of tractor operators. Making a management decision depends only on the agricultural producer, but the availability of tools to support it will make it correct.

\section{References}

1. H. Søgaard, C. Sørensen, A Biosystems Engineering 89(1), 13-28 (2014) doi.org: 10.1016/j.biosystemseng.2004.05.004

2. M. Duru, O. Therond, Agronomy for Sustainable Development 35(4), 1237-1257 (2015)

3. Y. Gadanakis, R. Bennett, J. Park, F. Jose, Journal of Environmental Management 150, 288-298 (2015) doi.org:10.1016/j.jenvman.2014.10.005

4. Q. Zhou, J. Lou, F. Xie, Q. Liu Zhou, International Journal of Digital Content Technology and its Applications 5(6), 337-334 (2011) doi:10.4156/jdcta.vol5.issue6.41

5. M. Ahmed Mohamed, A. Noureldin Osman Kheiry, A. Elshiekh Rahama, A. Alwathig Alameen, Turkish Journal of Agriculture-Food Science and Technology 5(7), 739-744 (2017) doi.org:10.24925/turjaf.v5i7.739-744.1144

6. D. Pannell, R. Llewellyn, M. Corbeels, Agriculture, ecosystems \& environment 187, 52-64 (2014) doi.org:10.1016/j.agee.2013.10.014

7. M. Schut, L. Klerkx, J. Rodenburg, J. Kayeke, L. Hinnou, C. Raboanarielina, P. Adegbola, A.van Ast, L. Bastiaans, Agricultural Systems 132, 1-11 (2015) doi.org:10.1016/j.agsy.2014.08.009

8. N. Umarusman, T. Hacivelioğullari, D. Eylü,1 Ü. İktisadi, İ. Bilimler, Fakültesi Dergisi 33(1), 353-368 (2018) doi.org/10.24988/deuiibf.2018331743

9. A. Sopegnoa A. Calvoa, R. Berrutoa, P. Busatoa, D. Bocthis, Computers and electronics in agriculture 130, 158-168 (2016) doi.org:10.1016/j.compag.2016.08.017

10. E. Rodias, R. Berruto, P. Busato, D. Bochtis, C. Sørensen, K. Zhou, Sustainability 9(11), 1956 (2017) doi.org/10.3390/su9111956

11. I. Darnhofer, European Review of Agricultural Economics 41(3), 461-484 (2014) doi.org:10.1093/erae/jbu012

12. D. Bochtis, C. Sørensen, P. Busato, Biosystems engineering 126, 69-81 (2014) doi.org: 10.1016/j.biosystemseng.2014.07.012

13. M. Altieri, C. Nicholls, R. Montalba, Sustainability 9(3), $349 \quad$ (2017) doi.org:10.3390/su9030349

14. A. Lenski, E. Ivanov, E. Kazhdan, Proc. of the National Academy of Sci. of Belarus. Agrarian 2, 102-111 (2015)

15. B. Dokin, O. Elkin, A. Aletdinova, IOP Conference Series: Earth and Environmental Science 341(1), 012111 (2019)

16. B. Dokin, A. Aletdinova, M. Kravchenko, Journal of Physics: Conference Series 803(1), 012032 (2017) 